\title{
Psychiatric Aspects of Egyptian Women with Unexplained Infertility
}

\author{
Mohammed Hussain Mostafa ${ }^{1}$, Anwar Mohamed Elashram² \\ ${ }^{1}$ Department of Obstetrics and Gynecology, Faculty of Medicine, Ain Shams University, Cairo, Egypt \\ ${ }^{2}$ General Secretary of Mental Health, Cairo, Egypt \\ Email: ^moh_marwa_omar@hotmail.com
}

How to cite this paper: Mostafa, M.H. and Elashram, A.M. (2020) Psychiatric Aspects of Egyptian Women with Unexplained Infertility. Open Journal of Obstetrics and Gynecology, 10, 1331-1339.

https://doi.org/10.4236/ojog.2020.1090122

Received: May 29, 2020

Accepted: September 21, 2020

Published: September 24, 2020

Copyright () 2020 by author(s) and Scientific Research Publishing Inc. This work is licensed under the Creative Commons Attribution International License (CC BY 4.0).

http://creativecommons.org/licenses/by/4.0/

(c) (i) Open Access

\begin{abstract}
Background: The diagnosis of unexplained infertility may be very frustrating for infertile couples and they show higher depression levels when compared to fertile couples. Aim: To assess the psychiatric aspects of Egyptian women with unexplained infertility. Methods: 220 infertile women were included in this study (110 with unexplained infertility and 110 with explained infertility). The psychiatric aspect of these women was evaluated using the translated and validated Hamilton Anxiety Rating Scale and the Beck Depression Inventory-II. Findings: The number of women with mild depression was significantly higher in the unexplained infertility group (47/110 (42.7\%)) versus $(22 / 110(20 \%))$ in the explained infertility group $(P=0.007)$. The number of women with moderate anxiety was significantly higher in the unexplained infertility group $(26 / 110(23.6 \%))$ versus $(8 / 110(7.3 \%))$ in the explained infertility group $(P=0.003)$. Conclusion: The current study concluded that mild depression and moderate anxiety were significantly higher in the unexplained infertility group. It is crucial to identify infertility women who are in need of psychological support and counseling during infertility treatment, because the psychological disturbance of the infertile women may affect the outcome of infertility treatment.
\end{abstract}

\section{Keywords}

Psychiatric Aspects, Egyptian Women, Infertility, Depression, Anxiety

\section{Introduction}

Unexplained infertility usually refers to a diagnosis made in couples in whom all the standard investigations such as tests of ovulation, tubal patency and semen analysis are normal [1]. 
Unexplained infertility is a term that has been applied to about $30 \%-40 \%$ of infertile couples [1] [2].

The prognosis of unexplained infertility is worse when the duration of infertility is more than 3 years and the female partner is older than 35 years [1]. If the duration of infertility is less than 2 years, the prognosis is relatively good even without therapy, unless the female partner is older than 35 years [1].

Treatment of unexplained infertility is indicated if the duration of infertility is more than 2 years or the female is older than 35 years [1].

According to the evidence, in-vitro fertilization (IVF) is the best option for women who are older than 40 years of age. Two cycles of gonadotropin stimulation and intrauterine insemination (IUI) should be considered before offering the IVF treatment [2] [3].

In younger women, treatment policy should follow a stepwise manner of expectant management followed by stimulated intrauterine insemination (IUI) before moving to IVF [3].

The NICE (National Institute for Health and Care Excellence) guideline on fertility assessment recommended doing IUI for six cycles before IVF in women with unexplained infertility [1] [2] [3].

The diagnosis of unexplained infertility may be very frustrating for the infertile couple and the treatment is often interrupted by them if there is no explanation for the cause of infertility and no effective treatment [1].

Ruchi Galundia et al. concluded that the depression level of the infertile couples was significantly high compared to fertile couples [4]. They also concluded that the psychological status plays an important role in the pathogenesis of infertility and the exploration of such factors is important to manage the infertility problem with its multiple cultural and social impacts [4].

In addition; Karaca and Unsal, concluded that infertile women suffer from various psychosocial disorders because of their infertility problem [5].

So, this study was designed to assess the psychological aspects of Egyptian women with unexplained infertility.

\section{Materials and Methods}

The current cross-sectional comparative study was conducted in the infertility outpatient clinic of Ain Shams Maternity Hospitals in collaboration with psychiatry department over one year (from January 2018 till January 2019) after Ethical Committee approval of both departments (Obstetrics \& Gynecology and Psychiatric departments) and after informed written consent from the studied women.

Two hundred and twenty women were included in this study; they were divided into 2 groups: the unexplained infertility group (110 women) and the explained infertility group (110 women).

Unexplained infertility usually refers to a diagnosis made in couples in whom all the standard investigations such as tests of ovulation, tubal patency and se- 
men analysis are normal.

Women ranged in their age between 18 and 35 years old, diagnosed with unexplained infertility and who were able to read and write in Arabic language were included in this study.

Women with any psychiatric disorder, receiving anti-depressant medications, showing inability to complete the translated and validated Hamilton Anxiety Rating (HAM-A) Scale and the Beck Depression Inventory-II (BDI) or refusing to participate in the study were excluded.

Studied women were evaluated thoroughly by the following means; history, examination and infertility work up which was done according to the hospital protocol (Day 2 - 3 follicle stimulating hormone (FSH), luteinizing hormone $(\mathrm{LH})$, thyroid stimulating hormone (TSH), anti-Mullerian hormone (AMH), estradiol, progesterone and prolactin, serum quantitative human chorionic gonadotropin ( $\beta$-hCG), transvaginal ultrasonography (TVS), antral follicle count (AFC) hysterosalpingography (HSG) and office hysteroscopy and/or laparoscopy if indicated).

Male partners of the participants were subjected to thorough evaluation including; history, examination, semen analysis and andrology assessment in cases with abnormal semen analysis results.

The psychiatric aspect of the studied women including the anxiety and the depression status was evaluated using the translated and validated Hamilton Anxiety Rating (HAM-A) Scale and the Beck Depression Inventory-II (BDI) by an expert psychologist during the course of infertility diagnosis and treatment.

Beck Depression Inventory-II (BDI); the inventory composed of 21 groups of statements on a 4-points scale, each studied woman selected the best answer that matched her current status. Total score of 0 - 14 means no depression, 15 - 28 means mild depression, 29 - 42 means moderate depression and a total score $>$ 43 means severe depression [6].

Hamilton Anxiety Rating (HAM-A) Scale: it consists of 14 items; each of them defines and measures both psychic and somatic anxiety on a 4-points scale and each studied woman selected the best answer that matched her current status. Total score of 0 - 11 indicates no anxiety, 12 - 17 indicates mild anxiety, 18 - 22 indicates moderate anxiety, and a total score $>23$ indicates severe anxiety [7].

\subsection{Limitation of the Study}

The only limitation is women refusal to participate

\subsection{Factors Affecting the Psychiatric Approach to Egyptian Women with Unexplained Infertility}

1) There is an evidence showing that most infertile couples in developing countries are often the only way for women to enhance their status in the community is by having children, and in some communities the child bearing inability is almost always attributed to women so they are often blamed even if the cause of infertility does not relate to them. 
2) Frequent failures in remedying infertility.

3) Fear and anxiety from disclosure of infertility as persistence absolute infertility happens for many couples.

4) Society limiting fertility to age of 30 and social pressure on participants' husbands due to fertility related problems were the main concern of the husband is to have a family.

5) Feeling of loneliness and guilt of not being able to make their husband a father.

6) Sadness due to expressed worries by the family members, the bitter reactions of their community, or due to being blamed by their husbands for the infertility.

\subsection{Sample Size}

$\mathrm{G}^{\star}$ Power software used for calculation of the sample size $\left({ }^{\star}\right.$ Heinrich Heine Universität; Düsseldorf; Germany). Two hundred and twenty (220) infertile women in two groups needed to produce a statistically acceptable sample size.

\subsection{Statistical Analysis}

Statistical analysis was done using the SPSS (Statistical Package for the Social Science; version 22, IBM Corp, New York, USA) for Microsoft Windows. Data presented as mean \pm standard deviation (SD), number and percentage (\%). The Chi-square $\left(X^{2}\right)$ test was used for analysis of the qualitative variables and the Student $\mathrm{t}$ test used for analysis of quantitative variables. The outcome measures, the psychiatric aspects of the Egyptian women with unexplained infertility. $P$ values $<0.05$ was considered statistically significant.

\section{Results}

Two hundred and twenty infertile women were included in this study. They were divided into 2 groups: the unexplained infertility group (110 women) and the explained infertility group (110 women).

The two studied groups were matched with no significant difference regarding; the mean age $(P=0.7)$, the body mass index $(P=0.79)$, the duration of marriage $(P=0.9)$, the duration of infertility $(P=0.88)$, the occupation $(P=$ $0.80)$, the residence $(P=0.87)$ and the history of smoking $(P=0.81)$ (Table 1$)$.

Women of the unexplained infertility group had a normal infertility work-up (by definition). While causes of infertility in the explained infertility group varied between; polycystic ovary syndrome (PCOS) as the most frequent cause of infertility $(26.4 \%(29 / 110)$, endometriosis $(21.8 \%(24 / 110))$, tubal obstruction $(17.3 \%(19 / 110))$, peritoneal adhesions $(15.5 \%(17 / 110))$, uterine myomas $(12.7 \%$ (14/110)), endometrial polyps (4.5\% (5/110)) and bicornuate uterus (1.8\% (2/110)).

The number of women with mild depression was significantly higher in the unexplained infertility group $(47 / 110(42.7 \%))$ in comparison to the explained infertility group $(22 / 110(20 \%))(P=0.007)$. 
Table 1. Demographic data of the two studied groups.

\begin{tabular}{cccc}
\hline Variables & $\begin{array}{c}\text { Unexplained group } \\
\text { (number }=110)\end{array}$ & $\begin{array}{c}\text { Explained group } \\
(\text { number }=110)\end{array}$ & $\begin{array}{c}P \text { value }(95 \% \\
\text { Confidence Interval) }\end{array}$ \\
\hline Age (Years) & $29.5 \pm 5.7$ & $29.7 \pm 6.0$ & $0.7(-1.7,-0.2,1.3)$ \\
Body mass index $\left(\mathrm{kg} / \mathrm{m}^{2}\right)$ & $29.4 \pm 4.9$ & $30.6 \pm 5.3$ & $0.79(-2.5,-1.2,0.14)$ \\
Duration of Marriage (Years) & $6.8 \pm 3.8$ & $6.9 \pm 4.4$ & $0.9(-1.18,-0.1,0.98)$ \\
Duration of Infertility (Years) & $5.8 \pm 3.3$ & $5.4 \pm 3.7$ & $0.88(-0.5,0.4,1.3)$ \\
Occupation & & & 0.88 \\
Housewives & $81(73.6 \%)$ & $80(71.4 \%)$ & 0.80 \\
Working & $29(26.4 \%)$ & $32(28.6 \%)$ & 1.00 \\
Residence & & & 0.87 \\
Urban & $62(56.4 \%)$ & $65(58.0 \%)$ & 0.81 \\
Rural & $48(43.6 \%)$ & $47(42.0 \%)$ & \\
Smoking & $6(5.5 \%)$ & $7(6.3 \%)$ & \\
\hline
\end{tabular}

Data presented as mean \pm SD (Standard deviation) and number and percentage (\%). Student $\mathrm{t}$ test used for statistical analysis when the data presented as mean \pm SD. Chi-square test $\left(X^{2}\right)$ used for statistical analysis when the data presented as number and \%.

The number of women with no depression was significantly higher in the explained infertility group $(63 / 110(57.3 \%))$ versus $(52 / 110(47.3 \%))$ in the unexplained infertility group $(P=0.4)$.

The number of women with moderate depression was significantly higher in the explained infertility group $(16 / 110(14.5 \%))$ in comparison to the unexplained infertility group $(8 / 110(7.3 \%))(P=0.11)$.

The number of women with no anxiety was significantly higher in the explained infertility group $(71 / 110(64.6 \%))$ versus $(32 / 110(29.1 \%))$ in the unexplained infertility group $(P=0.001)$.

The number of women with mild anxiety was significantly higher in the unexplained infertility group $(30 / 110(27.3 \%))$ in comparison to the explained infertility group $(20 / 110(18.2 \%))(P=0.2)$ and the number of women with moderate anxiety was significantly higher in the unexplained infertility group $(26 / 110(23.6 \%))$ versus $(8 / 110(7.3 \%))$ in the explained infertility group $(P=$ 0.003) (Table 2).

\section{Discussion}

World Health Organization (WHO) listed the depression as the $4^{\text {th }}$ leading cause of global burden and disability [8].

The World Health Organization classified the psychosocial consequences of infertility into six levels, the first two levels are psychological outcomes (1) fear, guilt, self-blame; 2) marital stress) and the other levels are social outcomes of infertility; 3) mild marital or social violence, social isolation; 4) severe economic deprivation, moderate to severe violence, total loss of social status; 5) violence induced suicide, starvation/disease; 6) lost dignity in death) [9]. 
Table 2. Beck depression inventory-II and Hamilton anxiety rating scale of the two studied groups.

\begin{tabular}{cccc}
\hline Variables & $\begin{array}{c}\text { Unexplained group } \\
\text { Number }=110\end{array}$ & $\begin{array}{c}\text { Explained group } \\
\text { Number }=110\end{array}$ & $\boldsymbol{P}_{\text {value }}$ \\
\hline Beck Depression Inventory (BDI) Score & & & \\
No depression & $52(47.3 \%)$ & $63(57.3 \%)$ & 0.4 \\
Mild depression & $47(42.7 \%)$ & $22(20 \%)$ & $0.007^{*}$ \\
Moderate depression & $8(7.3 \%)$ & $16(14.5 \%)$ & 0.11 \\
Severe depression & $3(2.7 \%)$ & $9(8.2 \%)$ & 0.08 \\
Hamilton Anxiety Rating Scale (HAM-A) Scale & & & \\
No anxiety & $32(29.1 \%)$ & $71(64.6 \%)$ & $0.001^{*}$ \\
Mild anxiety & $30(27.3 \%)$ & $20(18.2 \%)$ & 0.2 \\
Moderate anxiety & $26(23.6 \%)$ & $8(7.3 \%)$ & $0.003^{*}$ \\
Severe anxiety & $22(20.0 \%)$ & $11(10 \%)$ & 0.07 \\
\hline
\end{tabular}

*: Significant difference. Chi-square test used for statistical analysis. Data presented as number and \%.

Infertility is a stressful life event and exposure to stressful stimuli can lead to a variety of secondary diseases such as anxiety, depression, immune suppression as well as reproductive dysfunction [10].

Al-Asadi and Hussein found the prevalence of depression among infertile women in Iraq was $68.9 \%$ and it was significantly related to the duration of infertility and the threat of husband's remarriage [11].

Al-Asadi and Hussein concluded that the infertile women need psychological assessment and intervention as a part of their medical treatment counseling [11].

A cross-sectional study was conducted by Maroufizadeh et al., in Tehran (155 infertile women undergoing in-vitro fertilization (IVF) were included) to evaluate the factors associated with poor quality of life (QoL) among Iranian infertile women undergoing IVF [12].

Maroufizadeh et al. found the quality of life (QoL) to be worse in women with high depression and anxiety due to failure of the infertility treatment and unexplained infertility [12].

In addition; the current study showed that the mild depression and moderate anxiety were significantly high in the unexplained infertility group compared to the explained infertility group.

It is crucial to identify infertility women in need of psychological support and counseling during infertility treatment, because the psychological disturbance of the infertile women may adversely affect the outcome of infertility treatment.

Gabi Aisemberg Romano et al. found that there are some differences between infertile women, with women of explained infertility having stronger tendency for positive self-presentation and denial of weakness in comparison to those with unexplained infertility [13].

$D$, De Berards et al. found that women with infertility showed psychological 
distress about $48 \%$ - 96\%. The most common reactions were shock, anger, guilt, marital distress, lowered self-esteem, sexual dysfunction and social isolation [14].

Gameiro et al. concluded that the routine psychosocial care reduces stress and concerns about medical procedures, improves lifestyle outcome, patient well-being and compliance with treatment [15].

In addition; Yilmaz and Kavak, concluded that the health care professionals should be aware of the psychological issues faced by infertile individuals and the psychiatric counseling should be included in the diagnostic and treatment process of infertility [16].

The current study is the first study conducted to evaluate the psychiatric aspects of Egyptian women with unexplained Infertility and women refused to participate was the only limitation faced during conduction of this study.

We are in need of further future studies to assess the outcome of the infertility treatment on the psychiatric and psychological aspects of the infertile women.

\section{Conclusion}

The current study concluded that mild depression and moderate anxiety were significantly high in the unexplained infertility group. It is crucial to identify infertility women in need of psychological support and counseling during infertility treatment, because the psychological disturbance of the infertile women may affect the outcome of infertility treatment.

\section{Acknowledgments}

Authors are grateful for the women who agreed and gave consent to be included in this study.

\section{Ethical Approval}

All procedures performed in studies involving human participants were in accordance with the ethical standards of the institutional and/or national research committee and with the 1964 Helsinki declaration and its later amendments or comparable ethical standards. This study received approval by local institutional ethical committee of Ain Shams University Hospital and an informed consent was obtained from all individual participants included in the study.

\section{Consent to Participate}

Written consent has been acquired from participants after explaining the study design.

\section{Authors' Contributions}

Mohammed Hussain Mostafa is the corresponding author and responsible for the idea of the study, the data collection and analysis, the intellectual content, the writing and editing of the manuscript and the final revision before publica- 
tion.

Anwar Mohamed Elashram: psychiatric follow up of the cases, data collection and revision of the manuscript.

\section{Conflicts of Interest}

The authors declare no conflicts of interest regarding the publication of this paper.

\section{References}

[1] Ray, A., Shah, A., Gudi, A. and Homburg, R. (2012) Unexplained Infertility: An Update and Review of Practice. Reproductive BioMedicine Online, 24, 591-602. https://doi.org/10.1016/j.rbmo.2012.02.021

[2] Gunn, D.D. and Bates, G.W. (2016) Evidence-Based Approach to Unexplained Infertility: A Systematic Review. Fertility and Sterility, 105, 1566-1574. https://doi.org/10.1016/j.fertnstert.2016.02.001

[3] Abdelazim, I.A., Purohit, P., Farag, R. and Zhurabekova, G. (2018) Unexplained Infertility: Prevalence, Possible Causes and Treatment Options. A Review of the Literature. Journal of Obstetrics and Gynecological Investigations, 1, 17-22. https://doi.org/10.5114/jogi.2018.74250

[4] Galundia, R., Sethia, R. and Sharma, V. (2015) Comparative Study of Depression Level among Fertile and Infertile Couples. International Journal of Applied Research, 1, 920-925.

[5] Karaca, A. and Unsal, G. (2015) Psychosocial Problems and Coping Strategies among Turkish Women with Infertility. Asian Nursing Research, 9, 243-250. https://doi.org/10.1016/j.anr.2015.04.007

[6] Wu, P.C. (2017) Longitudinal Measurement Invariance of Beck Depression Inventory-II in Early Adolescents. Assessment, 24, 337-345.

https://doi.org/10.1177/1073191115608941

[7] Ball, S.G., Lipsius, S. and Escobar, R. (2015) Validation of the Geriatric Anxiety Inventory in a Duloxetine Clinical Trial for Elderly Adults with Generalized Anxiety Disorder. International Psychogeriatrics, 27, 1533-1539.

https://doi.org/10.1017/S1041610215000381

[8] Ferrari, A.J., Charlson, F.J., Norman, R.E., Patten, S.B., Freedman, G., Murray, C.J., et al. (2013) Burden of Depressive Disorders by Country, Sex, Age, and Year: Findings from the Global Burden of Disease Study 2010. PLOS Medicine, 10, e1001547. https://doi.org/10.1371/journal.pmed.1001547

[9] Griffin, P.D. (2002) Current Practices and Controversies in Assisted Reproduction: Report of a Meeting on Medical, Ethical and Social Aspects of Assisted Reproduction, Held at WHO Headquarters in Geneva, Switzerland. World Health Organization.

[10] Lynch, C.D., Sundaram, R., Maisog, J.M., Sweeney, A.M. and Buck Louis, G.M. (2014) Preconception Stress Increases the Risk of Infertility: Results from a Couple Based Prospective Cohort Study-The Life Study. Human Reproduction, 29, 1067-1075. https://doi.org/10.1093/humrep/deu032

[11] Al-Asadi, J.N. and Hussein, Z.B. (2015) Depression among Infertile Women in Basrah, Iraq: Prevalence and Risk Factors. JCMA, 78, 673-677.

https://doi.org/10.1016/j.jcma.2015.07.009 
[12] Maroufizadeh, S., Hosseini, M., Rahimi Foroushani, A., Omani-Samani, R. and Amini, P. (2018) The Effect of Depression on Quality of Life in Infertile Couples: An Actor-Partner Interdependence Model Approach. Health and Quality of Life Outcomes, 16, 73. https://doi.org/10.1186/s12955-018-0904-0

[13] Romano, G.A., Ravid, H., Zaig, I., Schreiber, S., Azem, F., Shachar, I. and Bloch, M. (2012) The Psychological Profile and Affective Response of Women Diagnosed with Unexplained Infertility Undergoing In Vitro Fertilization. Archives of Women's Mental Health, 15, 403-411. https://doi.org/10.1007/s00737-012-0299-6

[14] De Berardis, D., Mazza, M., Marini, S., Del Nibletto, L., Serroni, N., Pino, M.C. and Di Giannantonio, M. (2014) Psychopathology, Emotional Aspects and Psychological Counselling in Infertility: A Review. Clinical Therapeutics, 165, 163-169.

[15] Gameiro, S., Boivin, J., Dancet, E., de Klerk, C., Emery, M., Lewis-Jones, C., et al. (2015) ESHRE Guide Gabi Line: Routine Psychosocial Care in Infertility and Medically Assisted Reproduction-A Guide for Fertility Staff. Human Reproduction, 30, 2476-2485. https://doi.org/10.1093/humrep/dev177

[16] Yilmaz, E. and Kavak, F. (2018) The Effect of Stigma on Depression Levels of Turkish Women with Infertility. Perspectives in Psychiatric Care, 55, 378-382.

https://doi.org/10.1111/ppc.12319 